\title{
AMBIENTALIZAC̣ÃO CURRICULAR EM CURSOS DE CIÊNCIAS BIOLÓGICAS, UNIVERSIDADE FEDERAL DE CAMPINA GRANDE, PARAÍBA
}

\author{
DAYANE DOS SANTOS SILVA - (https://orcid.org/0000-0002-1073-5495)* \\ Universidade Estadual Paulista de Mesquita Filho, Rio Claro, SP - Brasil
}

ROSA MARIA FEITEIRO CAVALARI - (https://orcid.org/0000-0002-3782-2396)** Universidade Estadual Paulista de Mesquita Filho, Rio Claro, SP - Brasil

RESUMO: Neste trabalho, buscou-se compreender o processo de ambientalização curricular, nos cursos de Ciências Biológicas, oferecidos pela Universidade Federal de Campina Grande, Paraíba (UFCG). A partir de uma pesquisa de natureza qualitativa do tipo "estudo de caso" foi realizada uma "análise documental" do Projeto Pedagógico, bem como das ementas e programas das disciplinas de três cursos de Ciências Biológicas da UFCG, PB. Foram realizadas, também, entrevistas semiestruturadas com os coordenadores desses cursos e professores responsáveis pelas disciplinas selecionadas. Com a análise dos dados, percebeu-se que esses cursos têm incorporado a temática ambiental em seus currículos, mas estão concentradas em componentes curriculares optativos. Ademais, constatou-se que a Ambientalização Curricular é um processo complexo.

Palavras-chave: Ambientalização curricular; Relação sociedade natureza; Educação superior.

\section{CURRICULAR SETTING IN BIOLOGICAL SCIENCE COURSES FROM UNIVERSIDADE FEDERAL DE CAMPINA GRANDE, PARAÍBA}

ABSTRACT: This work aimed to understand the process of curricular setting in Biological Sciences courses offered by Universidade Federal de Campina Grande, Paraíba (UFCG). From a research of qualitative nature, of a "Case Study" type, a document analysis of the Pedagogical Project was carried out, as well as the bibliography and programs of the disciplines of three Biological Sciences courses of the UFCG, Paraíba, Brazil. Semistructured interviews were also conducted with the coordinators of these courses and teachers responsible for the selected disciplines. With the data analysis, it was noticed that these courses have incorporated the environmental theme in their curricula, but
* Mestre em Educação pela Universidade Estadual Paulista

"Júlio de Mesquita Filho" (UNESP/Rio Claro). Doutoranda em Educação pela Universidade Estadual Paulista de Júlio de Mesquita Filho" (UNESP/Rio Claro). Participante do Grupo de Pesquisa "A Temática Ambiental e 0 Processo Educativo" da UNESP de Rio Claro. Rio Claro, SP. Brasil. E-mail:<dayanedosssilva@gmail.com >

** Doutora em Educação pela Universidade de São Paulo (USP), Pós-Doutora em Educação Ambiental pela Universidade de Quèbec a Montreal-Canadá.

Professora e Pesquisadora do Programa de Pós-Graduação em Educação da Universidade Estadual Paulista de "Júlio de Mesquita Filho" (UNESP/Rio Claro). Participante do Grupo de Pesquisa "A Temática Ambiental e o Processo Educativo" da UNESP de Rio Claro. Rio Claro, SP. Brasil.

E-mail:<rosamfc@rc.unesp.br > 
are concentrated in optional curricular components. Furthermore, it was found that the course setting is a complex process.

Keywords: Curricular greening; Relationship between society and nature; Higher Education.

\section{AMBIENTACIÓN CURRICULAR EN CURSOS DE LAS CIENCIAS BIOLÓGICAS, UNIVERSIDAD FEDERAL DE CAMPINA GRANDE, PARAÍBA}

RESUMEN: En este trabajo, se buscó comprender el proceso de ambientación curricular en los cursos de las Ciencias Biológicas, ofrecidos por la Universidade Federal de Campina Grande, Paraíba, Brasil (UFCG). A partir de una investigación de naturaleza cualitativa del tipo "estudio de caso", fue realizado un análisis documental del proyecto pedagógico, bien como de las bibliografías y programas de las disciplinas de tres cursos de las Ciencias Biológicas de la UFCG, Paraíba. Fueron realizadas, también, entrevistas semiestructuradas con los coordinadores de eses cursos y maestros responsables por las disciplinas seleccionadas. Con el análisis de los datos, se percibió que eses cursos han incorporado a la temática ambiental en sus currículums, pero están concentradas en componentes curriculares optativos. Además, se constató que la ambientación curricular es un proceso complejo.

Palabras clave: Ambientación curricular; Relación sociedad laturaleza; Educación Superior. 


\section{INTRODUÇÃO}

As discussões relativas à problemática ambiental, em diferentes eventos acadêmicos, bem como a criação de redes universitárias, no final do século XX, têm contribuído para intensificar o debate sobre a inserção da temática ambiental na educação superior e, na última década, sobre a sustentabilidade, tornando esses termos cada vez mais presentes para se fazer referência à dimensão ambiental em cursos e programas nas Universidades. O contexto universitário passou a aderir a "programas de economia de energia, reciclagem de materiais e preservação do seu entorno ecológico", ações que buscam diminuir a "pegada ecológica do funcionamento dessas instituições" (LEFF, 2010, p.161).

A partir da intensificação dessas iniciativas cresce, também, a necessidade de reflexões sobre as questões epistemológicas e políticas que envolvem a dimensão ambiental, em especial, nos currículos dos cursos strito sensu e lato sensu nas instituições de ensino superior. Diferente de outros locais, para Leff (2009, p. XVIII) as universidades são "instituições de pesquisa e docência; de conhecimento, saber e cultura, por isso a ambientalização das universidades passa, sobretudo, pela ambientalização do currículo universitário".

A introdução dos conceitos de Ambientalização e Ambientalização curricular no ensino superior é, relativamente, recente no campo da Educação e Educação Ambiental, estas surgem “[...] com um status de categorias em construção a partir dos estudos pioneiros da Rede de Ambientalização Curricular no Ensino Superior (ACES) ${ }^{2}$ " nos anos 2000 (CARVALHO; SILVA, 2014, p. 126). Mas, segundo as autoras, há uma "[...] certa lacuna e ainda um desafio a enfrentar" na "[...] definição de um marco conceitual comum para as noções de ambientalização e ambientalização curricular, bem como a consequente definição de indicadores de ambientalização. (CARVALHO; SILVA, 2004, p. 125).

Algumas iniciativas têm sido construídas nesse sentido, como os estudos desenvolvidos por algumas redes universitárias, como: a Rede Aces, a partir da elaboração de dez características tomadas como indicadores para a caracterização de um estudo ambientalizado e a Ariusa $^{3}$ (Rede de redes universitárias ambientais) que, segundo Figueiredo et al. (2015, p. 193), desenvolveu um "[...] conjunto de cento e quatorze indicadores, estruturados em três grandes setores: organização, docência e pesquisa, e gestão ambiental na universidade" resultante do Projeto Risu "Definición de indicadores para la evaluación de las políticas de sustentabilidad en Universidades Latinoamericanas".

Neste estudo, partimos da compreensão que a ambientalização curricular consiste na inserção de elementos da relação sociedade-natureza no currículo e programas de formação, no contexto universitário, e que segundo a Red Aces é um

\footnotetext{
proceso continuo de producción cultural tendiente a la formación de profesionales comprometidos com la búsqueda permanente de las mejores posibles entre la sociedade y la naturaleza, atendendo a los valores de la justicia, la solidaridad y la equidade, aplicando los princípios éticos universalmente reconocidos y el respeto a las diversidades (JUNYENT; GELI; ARBAT, 2003, p. 21).
} 
O processo de Ambientalização não se restringe a uma única "fórmula" para se concretizar, mas oferece diversas possibilidades que estão associadas desde a região na qual estão alocados os cursos até a relação que se tem com seus planos de ensino. Considerando, também, os diferentes interesses e posicionamentos conceituais oferecidos a seus discentes, bem como a relação que as problemáticas possuem no âmbito global/local (PENAGOS, 2011).

Contudo, mesmo havendo indícios da ambientalização curricular nos cursos e programas universitários, é necessário que se questione sobre quais aspectos relativos à temática ambiental ${ }^{4}$ tornam o currículo do curso ambientalizado. Assim como alguns questionamentos, por exemplo, "[...] quando se pode decidir que a dimensão ambiental foi incorporada? Que sinais os indicadores devem considerar?” Para Penagos (2011, p. 94), as respostas a esses questionamentos "[...] geram conflitos e dificultam o conceito de incorporação e do que se incorporam [...]", sendo necessário que esse seja objeto de investigação ao longo de muitos anos.

Em sua tese de doutoramento Rink (2014) analisou "[...] os processos de ambientalização curricular propostos e/ou investigados pelos trabalhos de pesquisa em EA voltados para a formação de professores e profissionais educadores ambientais, [...] no período de 1987 a 2009". A autora observou que o curso de Ciências Biológicas compreende um dos cursos que predominam no campo das pesquisas que investigam a inserção da temática ambiental na educação superior, tendo como foco a formação inicial e continuada (RINK, 2014, p. 7-8).

Tal análise sugere que a temática ambiental está bastante presente nesses cursos, mas a menção desta não explicita que perspectivas acerca da temática ambiental constituem o currículo dos cursos de Ciências Biológicas. Considerando que esses cursos tradicionalmente possuem suas atividades institucionais marcadas pelas discussões ambientais (AMORIN et al. (2002), justifica-se a relevância de se investigar o processo de Ambientalização curricular nos cursos de Ciências Biológicas na modalidade licenciatura da Universidade Federal de Campina Grande (UFCG).

Assim, considerando-se a pertinência de analisar as diferentes iniciativas que se voltam para inserção da temática ambiental nesses cursos, bem como a relevância desse contexto para formação inicial de professores, cabe questionar: os cursos de Ciências Biológicas oferecidos pela Universidade Federal de Campina Grande, Paraíba, têm incorporado a temática ambiental em seus currículos? Que temáticas ambientais têm sido privilegiadas? Esse estudo tem como objetivo principal compreender o processo de ambientalização curricular nos cursos de Ciências Biológicas oferecidos pela Universidade Federal de Campina Grande/PB.

\section{DELINEAMENTO DA PESQUISA}

A presente pesquisa é de natureza qualitativa do tipo "estudo de caso". Esse tipo de pesquisa, de acordo com Yin (2010, p. 39), é uma "investigação empírica que investiga um fenômeno da vida real em profundidade e quando esse entendimento engloba importantes condições contextuais altamente pertinentes ao fenômeno de estudo". A partir das condições contextuais do fenômeno a que a pesquisa se propôs estudar, entende-se que o estudo de caso possibilita 
"compreender uma instância singular da realidade, tanto multidimensional quanto historicamente situada” (LÜDKE; ANDRÉ 1986, p. 21).

Frente às questões apresentadas, justifica-se a realização desta pesquisa que tem como foco de análise três cursos de Ciências Biológicas, alocados na instituição pública de ensino superior, com maior número de cursos de licenciatura em Ciências Biológicas da Paraíba, a UFCG. Cabe destacar, que os cursos são relativamente recentes, sendo fundados entre o ano de 2005 e 2011, além disso, os Projetos Pedagógicos dos Cursos analisados são a primeira versão dos documentos e estavam em vigência durante a pesquisa.

O contexto analisado consiste em três campi da UFCG, situados em diferentes cidades, nos quais os cursos de Ciências Biológicas estão alocados. Os campi nos quais a pesquisa foi desenvolvida serão nomeados como campus I, campus II e campus III.

Para o desenvolvimento da pesquisa realizou-se a "análise documental" dos Projetos Pedagógicos dos Cursos (PPC), bem como das ementas e programas das disciplinas. Como critério de seleção das disciplinas, procurou-se identificar os elementos referentes à relação sociedade-natureza como indícios da inserção da temática ambiental em tais materiais. Essas disciplinas são apresentadas no Quadro 1.

Quadro 1. Disciplinas selecionadas para análise na pesquisa, distribuídas em seus respectivos campi, presentes nos Projetos Pedagógicos do Curso de Ciências Biológicas dos campi I, II, III.

\begin{tabular}{|l|l|}
\hline \multicolumn{2}{|c|}{ Campus I } \\
\hline \multicolumn{2}{|c|}{ Disciplinas } \\
\hline Ecologia geral & Biologia da conservação \\
\hline Ecologia de comunidades & Ecologia do semiárido \\
\hline Meio ambiente e sociedade & Ecologia humana \\
\hline Educação ambiental & Educação para convivência no semiárido \\
\hline Gestão e conservação de recursos ambientais & Etnozoologia \\
\hline Etnobotânica & Campus II \\
\hline \multicolumn{2}{|c|}{ Campus III } \\
\hline Ecologia geral & Ecologia de populações e comunidades \\
\hline Etnobotânica & Sociedade, ambiente e desenvolvimento \\
\hline \multicolumn{2}{|c|}{ sustentável. } \\
\hline Ecologia geral & Ecoturismo \\
\hline Fundamentos de etnoecologia & \\
\hline Educação ambiental & \\
\hline
\end{tabular}

Fonte: Projetos Pedagógicos dos cursos analisados.

Além da análise desses documentos, foram realizadas entrevistas semiestruturadas com os coordenadores atuais, bem como com os primeiros coordenadores dos cursos; também foram entrevistados os professores responsáveis pelas disciplinas selecionadas já ministradas, totalizando dezessete entrevistas (vide Quadro 2). 
Quadro 2. Quantificação das entrevistas realizadas com os participantes da pesquisa de cada campus.

\begin{tabular}{|l|c|c|c|}
\hline Participantes & Campus I & Campus II & Campus III \\
\hline Coordenadores atuais & 1 & 2 & 2 \\
\hline Primeiros coordenadores & 1 & 1 & 1 \\
\hline Professores & 5 & 1 & 4 \\
\hline Total & 7 & 4 & 6 \\
\hline
\end{tabular}

Fonte: Entrevistas com os participantes da pesquisa.

Para sistematização e organização dos dados, optou-se pela "triangulação de dados" devido à utilização de diferentes fontes de evidências, a qual se caracteriza como um importante ponto na coleta de dados de um estudo de caso, possibilitando a dedicação do pesquisador ao "problema em potencial da validade do constructo, uma vez que várias fontes de evidências fornecem essencialmente várias avaliações do mesmo fenômeno" (YIN, 2010, p. 128). Ao analisarmos os documentos selecionados e as entrevistas, buscamos utilizar o referencial teórico relativo ao processo de Ambientalização e Ambientalização Curricular no ensino superior.

\section{A RELAÇÃO SOCIEDADE NATUREZA NO CURRÍCULO DE CURSOS DE CIÊNCIAS BIOLÓGICÁS, UFCG}

A partir dos documentos analisados, foram identificadas, nos três campi, um conjunto de disciplinas nas quais a temática ambiental, particularmente, a relação sociedade natureza, estava presente. Tal relação pode ser compreendida como indícios do processo de Ambientalização curricular, como apresentado no Quadro 3, a partir dos excertos das ementas do PPC e dos programas das disciplinas analisadas.

Cabe ressaltar, que os itens que constituem a apresentação da disciplina na estrutura curricular variam entre os cursos analisados; assim, no curso do campus II, a estrutura compreende a ementa e referências bibliográficas sugeridas, já no campus I e III, estão presentes a ementa, objetivos e referências sugeridas. 
Quadro 3. Disciplinas selecionadas para análise, distribuídas em seus respectivos campi, presentes nos Projetos Pedagógicos do Curso de Ciências Biológicas dos campi I, II, III.

\begin{tabular}{|c|c|}
\hline \multicolumn{2}{|r|}{ Elementos da relação sociedade-natureza nas disciplinas analisadas } \\
\hline Disciplinas & Excertos das ementas e programas das disciplinas \\
\hline \multirow{2}{*}{$\begin{array}{l}\text { Ecologia geral } \\
(I ; I I ; I I I)\end{array}$} & $\begin{array}{l}\text { "[...] Ecologia e desenvolvimento sustentável. [...] Seminários sobre temas atuais } \\
\text { da problemática ambiental e educação ambiental" (III); }\end{array}$ \\
\hline & $\begin{array}{l}\text { "Introduzir o aluno ao conhecimento e aos conceitos gerais da ecologia [...] à } \\
\text { evolução dos ecossistemas e às consequências das interferências humanas no } \\
\text { meio ambiente" (I, p.99; III, p.66). }\end{array}$ \\
\hline \multirow{2}{*}{$\begin{array}{l}\text { Ecologia de } \\
\text { populações e } \\
\text { comunidades } \\
\text { (II) e Ecologia de } \\
\text { comunidades (I) }\end{array}$} & $\begin{array}{l}\text { "Formar sujeito observador da natureza, com capacidade para interpretá-la, } \\
\text { conservá-la, assim como seus recursos naturais visando melhoria das condições } \\
\text { de vida do homem e demais organismos" (III). }\end{array}$ \\
\hline & $\begin{array}{l}\text { Promover o desenvolvimento técnico-profissional e ético e as relações sócio- } \\
\text { ambientais que os conhecimentos thes responsabilizam à sociedade (I); }\end{array}$ \\
\hline \multirow{3}{*}{$\begin{array}{l}\text { “Fundamentos de } \\
\text { etnoecologia (III), } \\
\text { “Etnobotânica" (III; I); } \\
\text { “Etnozoologia" (I). }\end{array}$} & $\begin{array}{l}\text { “[...] o papel do conhecimento etnobotânico na descoberta de novas substâncias de } \\
\text { aplicação farmacêutica ou industrial, bem como, na conservação da biodiversidade } \\
\text { e no gerenciamento de recursos vegetais" (II, p. 91). }\end{array}$ \\
\hline & "Importância das crenças, rituais e tabus para conservação dos ecossistemas". (III) \\
\hline & "[...] considerações sobre a relação entre humanos e outros animais” (I). \\
\hline $\begin{array}{l}\text { Ambiente e } \\
\text { desenvolvimento } \\
\text { sustentável (II) e } \\
\text { Meio ambiente e } \\
\text { sociedade (I). }\end{array}$ & $\begin{array}{l}\text {-"Analisar a evolução conceitual do desenvolvimento sustentável para a formatação } \\
\text { do ideal da sustentabilidade ambiental e planetária". (I, p.125). }\end{array}$ \\
\hline \multirow{2}{*}{$\begin{array}{l}\text { Educação } \\
\text { ambiental (I; III) }\end{array}$} & $\begin{array}{l}\text { "Entender a sustentabilidade como categoria imprescindível para o desenvolvimento } \\
\text { humano e planetário do século XXI" }\end{array}$ \\
\hline & $\begin{array}{l}\text { Desenvolvimento sustentável: histórico e desafios. Propostas e estratégias para } \\
\text { o desenvolvimento sustentável. Histórico da Educação Ambiental no Brasil e no } \\
\text { mundo (III) }\end{array}$ \\
\hline Ecoturismo (III) & $\begin{array}{l}\text { "Oportunizar novos conhecimentos acerca das questões ambientais, promovendo } \\
\text { uma integralização entre o turismo e o meio ambiente, bem como incentivar a } \\
\text { conservação do patrimônio natural" (IIII). }\end{array}$ \\
\hline $\begin{array}{l}\text { Gerenciamento } \\
\text { de resíduo (III) }\end{array}$ & “[...] levantamento sócio-econômico-ambiental” (III). \\
\hline \multirow{2}{*}{$\begin{array}{l}\text { Ecologia do } \\
\text { semiárido (I) }\end{array}$} & $\begin{array}{l}\text { "Desequilíbrios ambientais rurais e urbanos (causas e consequências). } \\
\text { Desertificação. As populações humanas do semiárido". }\end{array}$ \\
\hline & $\begin{array}{l}\text { “[...] entender a relação sociedade-natureza como fenômeno cultural de } \\
\text { combinação entre autonomia e dependência" (I, p. 162). }\end{array}$ \\
\hline $\begin{array}{l}\text { Biologia da } \\
\text { conservação (I) }\end{array}$ & $\begin{array}{l}\text { "Identificar os componentes da biodiversidade e as perturbações decorrentes } \\
\text { das ações antropogênicas" [...] Biodiversidade e sociedade: valoração ambiental, } \\
\text { planejamento, política e organizações ambientais (I, p. 156). }\end{array}$ \\
\hline Ecologia humana (I) & $\begin{array}{l}\text { “Consumo e ambiente. Ecossistemas antrópicos e sociedade de consumo. Aldeia } \\
\text { global. Produção e distribuição de alimentos. Etnobiologia e sociedade humana. } \\
\text { Îndices sócio econômicos e ambientais” (I). }\end{array}$ \\
\hline $\begin{array}{l}\text { Educação para } \\
\text { convivência no } \\
\text { semiárido (I) }\end{array}$ & $\begin{array}{l}\text { “A crise ecológica- sustentabilidade - perspectivas de futuro. Economia e natureza } \\
\text { [...] impactos antrópicos sobre a biodiversidade [...] Unidades de conservação (II. }\end{array}$ \\
\hline
\end{tabular}

Fonte: Dados do Projeto Pedagógico dos cursos investigados. 
A partir da análise dos excertos presentes nas ementas dos PPC e nos programas das disciplinas analisadas, observou-se que das 59 disciplinas do campus I, 19\% contemplam elementos do processo de Ambientalização Curricular, no campus II, essa porcentagem diminui para 8\% das 63 disciplinas, bem como no campus III, no qual, das 62 disciplinas, 6,5\% apresentam indícios desse processo. Os componentes curriculares que abordam a relação sociedade natureza estão, em sua maioria, presentes em componentes optativos, como apresentado no Quadro 4.

Quadro 4. Quantificação dos componentes curriculares obrigatórios e optativos que constituem os PPC dos cursos analisados.

\begin{tabular}{|c|c|c|c|}
\hline Componentes curriculares & Campus I & Campus II & Campus III \\
\hline Quant. obrigatórias & 3 & 2 & 1 \\
\hline Quant. optativas & 8 & 2 & 4 \\
\hline Total no PPC & 59 & 62 & 63 \\
\hline
\end{tabular}

Fonte: Dados do Projeto Pedagógico dos cursos investigados.

Ao investigar o processo de Ambientalização, a partir da presença de elementos da relação sociedade natureza nas estruturas curriculares, percebeu-se que os cursos de Ciências Biológicas, ainda que apresentem alguns indícios dessa temática, estes ainda são incipientes. Tal abordagem, de modo geral, parte de ações e áreas tradicionais estudadas na base comum de tradição naturalista das Ciências Biológicas, como a Ecologia que, dentre outras áreas, acaba abrangendo as "questões ambientais", com exceção de disciplinas com abordagens mais direcionadas, como "Meio ambiente e Sociedade (campus I)". Cabe destacar, que no curso oferecido no campus I, apresenta-se um maior número de componentes curriculares, nos quais a temática ambiental está presente em relação aos outros campi.

Além disso, a concentração da temática ambiental, nas disciplinas optativas, também é relatada por Silva (2014), ao investigar o processo de Ambientalização Curricular no curso de licenciatura de Ciências Biológicas. De acordo com a autora "a temática ambiental é mais presente nas disciplinas optativas do que nas disciplinas obrigatórias", condição essa que, segundo os licenciandos entrevistados, "[...] da maneira como está estruturado e a carga horária muito grande, não favorece a oportunidade dos licenciandos cursarem essas disciplinas” (p. 89). Tal secundarização dessa temática está relacionada às condições de produção desses documentos que podem compreender tanto a formação dos docentes responsáveis pelo PPC, quanto ao atendimento às exigências de políticas curriculares nacionais. Tais questões serão discutidas no próximo item.

Após esse processo inicial de identificação dos indícios de Ambientalização Curricular, buscamos explorar as temáticas que foram abordadas com mais frequência nos materiais analisados, sendo elas: ética; relação de consumo e o ambiente; valoração da natureza; sustentabilidade e desenvolvimento sustentável; conservação do meio; interferência/impacto humano no meio; relação sociedade natureza e conhecimento ecológico tradicional. Dentre essas, destacamos as 
perspectivas relacionadas às cinco últimas temáticas, as quais são abordadas com maior frequência nos documentos, discutidas a seguir.

O desenvolvimento sustentável/sustentabilidade é uma das temáticas mais presentes nos textos das disciplinas analisadas; tal presença pode ser interpretada como resultado da influência do período determinado pela UNESCO como a "Década da Educação para o Desenvolvimento Sustentável" (2005-2014), temática essa presente no PPC do curso oferecido pelo campus II, que na introdução defende "[...] a necessidade da promoção do desenvolvimento sustentável, a busca da superação das desigualdades sociais e a construção da cidadania [...]” (p. 6). E a "pedagogia da sustentabilidade" como "pressupostos teóricos e filosóficos" que fundamentam o PPC do curso do campus I.

A abordagem dessa temática pode ser observada, também, em algumas ementas das disciplinas, como: Meio ambiente e sociedade no campus I, que tem como um dos seus objetivos "analisar a evolução conceitual do desenvolvimento sustentável para a formatação do ideal da sustentabilidade ambiental e planetária" (PPC, p. 125); no campus II, a disciplina Sociedade, ambiente e desenvolvimento sustentável busca discutir a questão ambiental e o desenvolvimento sustentável a partir das "origens da questão ambiental, das perspectivas sociológicas da crise ambiental, da globalização e do desenvolvimento sustentável, dos impactos ambientais, e das correntes da ética." (p. 89); a disciplinas de Educação Ambiental, no campus III, propõe-se a discutir alguns aspectos relativos ao desenvolvimento sustentável, a partir do "histórico e desafios e de propostas e estratégias para o desenvolvimento sustentável”, (p. 98).

A abordagem do tema desenvolvimento sustentável, tanto na introdução dos PPC, quanto nas ementas e programas das disciplinas, sugere a influência do discurso da "Educação para o desenvolvimento sustentável", como já mencionado, que passou, cada vez mais, a ocupar espaços no âmbito internacional, substituindo o termo da Educação Ambiental em alguns contextos. Para González-Gaudiano (2005), contrariamente ao que sugere o cenário internacional que atribui o debate das questões sociais ao desenvolvimento sustentável, na América Latina e em algumas instituições espanholas, essas questões já eram contempladas pela Educação Ambiental.

Além da frequência dessa temática nos PPC analisados, observou-se, também, que os termos desenvolvimento sustentável e sustentatbilidade são apresentados como sinônimos, não sendo possível uma construção que possa sugerir uma diferenciação conceitual entre eles. A ausência de uma diferenciação ou definição sobre sustentabilidade também foi identificada por Gonzalez (2008), ao pesquisar a temática ambiental em cursos de Turismo no Estado de São Paulo. Segundo a autora "[...] a ideia de sustentabilidade pareceu ser o mote dos projetos pedagógicos dos cursos, porém ela não é definida nos documentos” (p.130).

A ausência de diferenciação entre esses conceitos é característica de alguns debates que envolvem essa temática e ao se discutir as questões ambientais podem sugerir um comprometimento na compreensão dos limites e das restrições da exploração dos recursos naturais, possibilitando ao mercado o uso desses recursos orientados pelo crescimento econômico (GUTIÈRREZ; BENAYAS; CALVO, 2006). Ademais, a ausência de uma plena compreensão desses conceitos pode resultar, algumas vezes, em dificuldades para sua incorporação no campo prático 
nas universidades. Além disso, quando estão presentes, não figuram entre os eixos principais das estruturas das IES (GONZÁLEZ-GAUDIANO et al., 2015).

Devido à inserção crescente desses conceitos nos espaços educativos é necessário que a universidade, enquanto local de produção do conhecimento, possa problematizá-los, buscando esclarecer as contradições envolvidas neles. Durante uma das entrevistas, ao mencionar a disciplina "Sociedade, ambiente e desenvolvimento sustentável”, um dos professores do campus II demonstrou certo incômodo em relação ao nome da disciplina, tal posicionamento reflete, também, os diferentes pontos de vista frente à inserção dessa temática. O professor considera que é importante estar atento a esse termo, “[...] eu tenho um certo cuidado quando uso esse termo sustentável, esse termo 'sustentável', ele meio que machuca meu ouvido".

Dessa maneira, a ausência de uma compreensão clara do conceito da sustentabilidade e das diferentes dificuldades encontradas no âmbito prático, tem se caracterizado enquanto um dos problemas que segundo GonzálezGaudiano et al. (2015, p.77) dificulta a realização de mudanças mais substanciais, tanto nas estruturas acadêmicas quanto na gestão das Universidades e, assim, os "[...] principais efeitos incidem em que as propostas de sustentabilidade vão de encontro a um teto de cristal nas próprias instituições".

A temática conservação do meio se revelou como uma das mais frequentes nos documentos analisados, uma perspectiva já bastante presente nas áreas do conhecimento compreendidas pelas Ciências Biológicas. As iniciativas e discussões sobre a conservação da natureza baseiam-se, dentre outros conceitos, no entendimento de "área protegida" que de acordo com "a Convenção sobre diversidade biológica" (CDB), "significa uma área definida geograficamente que é destinada, ou regulamentada, e administrada para alcançar objetivos específicos de conservação" (CDB, p. 9). Iniciativas de proteção do meio constituem uma possibilidade para conservação da biodiversidade, estas ações estão distribuídas nos diferentes ecossistemas, biomas terrestres e marinhos, sendo as bases que fundamentam a maioria das "estratégias nacionais e internacionais de conservação, [...] para atuar como refúgios para as espécies e para manter os processos ecológicos que não podem sobreviver em paisagens terrestres e marinhas mais intensamente geridas" (IUCN).

Destarte, a conservação da natureza vem se constituindo como uma das principais estratégias que buscam favorecer a proteção da biodiversidade frente às problemáticas ambientais e a intensificação do processo de degradação do ambiente, em decorrência da relação sociedade natureza. Compreensão essa explicitada pelo professor do campus II, ao comentar a dinâmica das disciplinas ministradas por ele,

[...] ecologia de populações e comunidades que também tem um enfoque importante, no final da disciplina a gente trabalha com a conservação, então também tem um enfoque importante no sentido assim de puxar o conhecimento ecológico para vida real, para os problemas ambientais, dentro do outro enfoque, por exemplo, biologia da conservação vai tratar das espécies ameaçadas e aí as espécies estão ameaçadas por quê? Então, as maiores causas de ameaça das espécies são em função da interferência do homem no ambiente [...] (Professor do campus II) 
Essa preocupação também pode ser observada na ementa de algumas disciplinas, como a Ecologia de comunidades do campus II, na qual se objetiva "formar sujeito observador da natureza, com capacidade para interpretá-la, conservá-la, assim como seus recursos naturais visando melhoria das condições de vida do homem e demais organismos" (programa da disciplina). Assim como na disciplina de Biologia da conservação que tem como um dos objetivos possibilitar aos alunos "aprender conhecimentos biológicos para a compreensão e implementação de processos de conservação e preservação ambiental” (p. 156, campus I).

O desenvolvimento de ações voltadas para a proteção da natureza, como mencionado nos excertos anteriores, ao longo dos anos tem se constituído como elemento desafiador para a sociedade. Isso porque, essas ações estão envoltas por uma "rede complexa de motivações e contradições [...]". Contradições essas que dizem respeito à relação que o humano estabelece, a partir de iniciativas de proteção à natureza e as quais podem caracterizar-se como "abordagens com perspectivas antagônicas: a natureza a serviço do homem ou o homem subordinado a ela? Em síntese, a natureza como externalidade ou internalidade?" (MEDEIROS; IRVING; GARAY, 2004).

Esse antagonismo é caracterizado pela importância de ações que invistam na proteção da natureza, frente ao modelo de produção e consumo atual, sobretudo pela construção de certa externalidade do humano em relação à natureza. Essas propostas assimilam o debate ecológico convertendo "os processos ecológicos [...] em capital natural, humano e cultural” (LEFF, 2008, p. 23). Compreensões que podem influenciar o entendimento de futuros profissionais, que atuarão nos espaços de educação formal, contribuindo para naturalização da apropriação e privatização dos bens comuns naturais e da própria relação dos humanos.

Na temática "Interferência" das atividades humanas na natureza, buscase discutir as consequências das diferentes ações humanas atualmente, assim como os processos de modificação da natureza ao longo dos anos, culminando em desastres ecológicos, tal como referenciado nas ementas de algumas disciplinas, como no objetivo geral da disciplina de Ecologia geral, do campus II, no qual há o entendimento da ação humana na natureza enquanto um fator danoso para as relações ecológicas, assim a disciplina se propõe a "introduzir o aluno ao conhecimento e aos conceitos gerais da ecologia [...] à evolução dos ecossistemas e às consequências das interferências humanas no meio ambiente" (p. 66). No campus I, a disciplina de Biologia da conservação tem como um dos objetivos "identificar os componentes da biodiversidade e as perturbações decorrentes das ações antropogênicas" (p. 156).

Essas discussões também foram relatadas pelos participantes da pesquisa, como os professores do curso dos campi II e I, que descrevem algumas problemáticas ambientais causadas por ações humanas no ambiente ao comentarem sobre a dinâmica das disciplinas ministradas. Um dos professores entrevistados chama atenção para um dos principais problemas ambientais enfrentados pela cidade na qual está alocado o campus II, ou seja, o lixão da cidade. Na tentativa de encontrar alguma alternativa, o professor já buscou mobilizar alguns alunos que participam do Centro Acadêmico, tal como explicitado no excerto a seguir: 
[...] os temas atuais em ecologia são aqueles temas que vão abordar todos os problemas ambientais causados pela interferência do homem no ambiente, as questões antrópicas [...] a questão do lixo, da água, da energia, do consumo, do uso da terra, todas essas questões aí voltadas à interferência do homem no ambiente [...] E aí, aqui (na cidade) tem um problema muito sério no lixão, nosso lixão pega fogo e fica uma semana, quinze dias, queimando sem parar [...] uma coisa que eu fiz foi reunir um pessoal do CA do Centro Acadêmico para ver se a gente fazia alguma coisa em conjunto [...] (Professor do campus II). ao afirmar que:

O problema do lixo, também é mencionado pelo professor do campus III

[...] então vem aí atividades antrópicas influenciando o meio, poluição ambiental, o foco mais específico humano, eu trabalho na última disciplina (Sociedade e meio ambiente), porque aí eu trabalho a parte de ecossistemas e biomas e a influência antrópica, então a gente vê a questão do lixo, poluição de água, de ar de lixo, mas de forma geral eu tento trazer para a disciplina a ação do ser humano (Professor do campus III).

A ideia de conduzir o aluno à problematização das interferências humanas é interessante na medida em que possibilita uma aproximação do aluno em formação inicial, não apenas dos processos de interação e desenvolvimento biológico na natureza, mas também, do ser humano enquanto parte desta, atentando-se para ações que intensificam ou são causadoras de impactos no ambiente. Essa ideia pode contribuir para compreensão da problemática ambiental e, principalmente, da degradação ambiental causada pela maneira como tem sido estabelecida as relações entre a sociedade e natureza. Cabe destacar, no entanto, que dependendo da forma como é explorada, pode induzir a uma compreensão da "natureza enquanto uma reserva de bem, beleza e verdade" ressaltada por Carvalho (2001, p. 75).

A temática relação sociedade-natureza, ao ser abordada nos documentos analisados, está relacionada à ideia de interdependência, a partir da "autonomia e dependência", que pode contribuir para a construção de "atitudes e práticas socioambientais" (PPC III, p. 122). A ideia de interdependência nessa temática reflete a compreensão que concebe que essas problemáticas não são apenas ambientais, mas também sociais. Compreensão essa que pode ser observada no relato de um dos professores do curso do campus II, ao trabalhar com pesquisas voltadas para o conhecimento tradicional de agricultores, a partir do questionamento sobre o entendimento de natureza dessas pessoas e sua relação com o meio em que vivem, conforme pode ser observado no excerto abaixo:

[...] a gente quer saber desse olhar deles e os elementos que compõe a natureza no seu dia a dia. Como é que eles se servem da natureza? Como é que eles percebem a natureza? Como é que ele vê esse contexto? Ele se vê no contexto do ambiente que ele vive? [...] A gente se enxerga como ser social e, ao mesmo tempo, como ser biológico também, pela minha formação em Biologia não posso deixar de pensar no homem como um animal, então a gente depende do meio, a gente faz uma pressão, mas também sofre uma pressão evolutiva e, ao mesmo tempo, nós somos sociais. (Professor do campus III) 
Ao refletir sobre essa relação, faz-se necessário, também, problematizar a oposição desse reconhecimento do humano, enquanto natureza, a partir da "objetificação" dessas relações que se estabelecem diante da natureza. Assim, ela torna-se propriedade privada e logo pode ser mercantilizada, ainda em nome de benefícios e necessidades presentes no mundo, tal como a fome e um futuro necessário para as próximas gerações, em que os "recursos" não estejam disponíveis.

Sob essa perspectiva, justifica-se e legitima-se toda e qualquer apropriação da natureza e do humano, tal como explicitado por Adorno e Horkheimer (1985, p. 35), quando afirmam que o "preço da dominação não é meramente a alienação dos homens com relação aos objetos dominados [...] as próprias relações dos homens foram enfeitiçadas, inclusive as relações de cada indivíduo consigo mesmo".

Frente à necessidade de desvelar as contradições que perpassam a relação sociedade natureza, um dos professores do campus I explicita a importância de se desenvolver o "olhar crítico" durante a formação inicial, na tentativa de desnaturalizar os discursos que se fazem consensos na sociedade, por isso ele busca desenvolver suas atividades baseadas na perspectiva da "formação do sujeito ecológico". Veja-se,

[...] esse aluno que a gente tá trabalhando precisa desenvolver um olhar crítico, um olhar de pesquisador, de investigador da situação, para não achar que tudo que tá aí é natural, sempre foi assim e vai ficar, porque se a gente pensar assim ele vai reproduzir o que a sociedade de hoje já faz. Então nessas disciplinas eu trabalho nessa perspectiva e a literatura que eu trabalho é a que trata da formação do sujeito ecológico. (Professor do campus I).

O relato desse professor pode ser interpretado como tributário da característica da Red Aces "compromisso com a transformação das relações sociedade-natureza", que se esboça "entre os campos da ação e do pensamento humano, na busca de modificar e, muitas vezes, melhorar as condições de nossa existência em sociedade, tendo na relação com a natureza pontos de tensionamento" (OLIVERA JÚNIOR et al., 2003, p. 55).

Emrelaçãoàtemática "conhecimentoecológicotradicional", pode-seobservar que ela está presente na estrutura curricular dos três campi investigados, distribuída nas disciplinas de Etnobotânica, Etnozoologia e Fundamentos de Etnobotânica. Essas disciplinas buscam a compreensão do conhecimento desenvolvido por determinadas culturas, a partir da interação dessas com a biodiversidade, ou seja, a compreensão que os moradores de determinada comunidade possuem e a relação desenvolvida por eles no ambiente. Essa compreensão também é ressaltada no relato do professor do campus III, ao caracterizar as pesquisas que se voltam para a Etnobiologia. Conforme pode ser observado no que segue:

[...] o pensar trabalhar na Etnobiologia, quais são os cuidados que a gente tem que ter em campo ao lhe dar com o ser humano, já que a gente quer saber desse olhar deles, os elementos que compõe a natureza no seu dia a dia, como é que eles se servem da natureza? Como é que eles percebem a natureza? Como é que ele ver esse contexto, ele se ver no contexto do ambiente que ele vive? (Professor do campus III). 
Ao abordar essa temática, as discussões se concentram, principalmente, no conhecimento sobre a fauna e flora desenvolvido por determinadas populações tradicionais ${ }^{5}$, assim como, na contribuição da apropriação desse conhecimento para conservação do meio e a influência de situações culturais, ecológicas e sociopolíticas da região/comunidades.

No entanto, cumpre destacar, que há também a ideia do conhecimento etnobotânico, em seu caráter utilitário, a partir da aplicabilidade no campo industrial e farmacêutico, assim como, a ênfase em ações de conservação e/ou gerenciamento do meio, e a menção da natureza enquanto recurso. Tal como explicitado nos objetivos do programa da disciplina de Etnobotânica do campus II, nos quais um deles enfatiza a apropriação do conhecimento tradicional das comunidades pelo mercado, sugerindo "[...] facultar a aplicação desses conhecimentos nos diversos setores e segmentos da sociedade que se beneficiam dos resultados das pesquisas etnobotânicas (indústria, laboratórios farmacêuticos, ONGs etc.)".

Tal abordagem sugere a predominância de uma perspectiva utilitarista, no que tange à utilização das plantas pelas comunidades e a apropriação dessas por outros segmentos da sociedade com fins lucrativos, sem haver, em algumas situações, um devido retorno para essas comunidades. Nesse cenário, destaca-se a importância de debates sobre o necessário diálogo entre as diferentes áreas do conhecimento para formação profissional inicial.

$\mathrm{Na}$ disciplina de Fundamentos de Etnoecologia no campus III, discute-se a relação que as populações tradicionais estabelecem com o meio a partir da sua dinâmica, “[...] etnoconservação da biodiversidade." "Importância das crenças, rituais e tabus para conservação dos ecossistemas" (p. 107), assim como a possibilidade de aproximação desse conhecimento com as práticas educativas, tendo em vista que o curso é de licenciatura, além da importância dessa temática para compreensão da relação sociedade natureza na formação do professor de Biologia e Ciências.

\section{ASPECTOS RELATIVOS À AMBIENTALIZAC̣ÃO CURRICULAR IDENTIFICADOS NOS CURSOS ANALISADOS}

Durante a análise do processo de Ambientalização curricular tanto a partir dos PPC e programas das disciplinas analisados, quanto das entrevistas com os professores e coordenadores dos cursos observou-se alguns aspectos que influenciaram a inserção da temática ambiental no currículo dos cursos investigados, como: a relação entre o conhecimento oficial e o conhecimento ensinado, e a interdisciplinaridade e disciplinaridade, discutidos a seguir. Cabe destacar, que esses aspectos também estão presentes nas discussões sobre o processo educativo de forma geral, assim algumas das dificuldades relatadas pelos participantes são desafios enfrentados pela área da Educação e da Educação Ambiental.

Sobre a relação estabelecida entre o "conhecimento oficial" e o "conhecimento ensinado", compreende-se que, paralelas à influência dos aspectos profissionais e de atuação docente, estão as exigências de órgãos como o Conselho Federal de Biologia (CFBio), e as políticas públicas educacionais que regem e regularizam a Educação como um todo. Tais políticas e o CFBio, por sua vez, constituem-se como um "currículo oficial" que exprime um conjunto de leis e 
normas que regularizam o currículo, indicando o conhecimento a ser ensinado no contexto da educação formal. As orientações oficiais que influenciam a construção dos Projetos Políticos Pedagógicos dos cursos e que, consequentemente, a partir desses são elaborados os programas das disciplinas a serem ministradas, podem ser caracterizados como processos de seleção e distribuição do conhecimento.

Nesse processo, o docente não é um profissional que age livremente em relação às políticas nacionais educacionais, mas além dessas exigências, também está situado em uma instituição estruturalmente organizada e preestabelecida, de maneira que o professor "não decide sua ação no vazio, mas no contexto da realidade de um local de trabalho, numa instituição que tem suas normas de funcionamento marcadas, às vezes, pela administração e pela política curricular" (SACRISTÁN, 2000, p.166).

Além das políticas educacionais e das estruturas institucionais, outros "mecanismos sutis" presentes no cotidiano docente podem dificultar a inserção da temática ambiental no currículo, desde a falta de articulação entre professores até a influência da especialização das áreas do conhecimento,

[...] falta de diálogo entre os professores concorreria com os mecanismos mais sutis pelos quais as disciplinas acadêmicas tendem a evolver, como as disciplinas científicas, em direção à especialização e à hierarquização, que representariam entraves para a integração de novos temas e práticas sociais notadamente transversais (PAVESI, 2007, p.174).

Algumas dessas questões podem influenciar a seleção dos componentes curriculares que compõem o PPC de um curso de formação inicial, bem como a inserção de propostas que contemplem a temática ambiental, tal como relatado pelo coordenador inicial do campus I ao mencionar a visita de representantes do Instituto Nacional de Estudos e Pesquisa (INEP) para avaliação do PPC. Segundo o coordenador, "Quando os avaliadores do INEP vieram analisar, eles me questionaram muito, principalmente com a (disciplina) de Meio ambiente e sociedade, mas o que você quis dizer com isso? Eles foram ver a ementa para poder entender a proposta".

Assim, o processo de seleção e distribuição do conhecimento constituise enquanto um espaço de disputa a partir da relação que se estabelece entre o docente, o "currículo oficial" e as condições do contexto no qual esse currículo é construído. Condições presentes, também, no relato do primeiro (e atual) coordenador do campus III, que enfatiza a exigência da Resolução n ${ }^{\circ} 300$, de 3 dezembro de 2012. O referido documento determina um aumento na carga horária dos cursos de Ciências Biológicas e as condições que os currículos dos cursos possuem para adequar-se às exigências como essas. Veja-se:

[...] a gente tem que seguir a legislação do conselho de Educação [...] eu não concordo que seja por imposição do CFBio ou de CRBio, porque eu acho que a função deles é regularizar, fiscalizar e não essa coisa de imposição, de você ter uma carga horária. Eu acho que o Conselho Nacional de Educação observa isso, o que a gente precisa para formação de professores, então a gente está tentando não enxugar, porque não dá, mas também não acrescentar, porque se a gente fosse colocar tanta coisa o curso noturno iria para quantos anos? (Coordenador do campus III). 
O relato dos coordenadores dos cursos investigados reflete as diferentes ações docentes frente às prescrições do currículo oficial na construção dos PPC, tais negociações são imprescindíveis a partir da interação e ação frente a esse currículo. Segundo Sacristán (2000, p.166), "essa capacidade de modelação que os professores têm é um contrapeso possível se é exercida adequadamente e se é estimulada como mecanismo contra-hegemônico".

Assim, atuando dentro de uma lógica estruturalmente preestabelecida, a ação docente não é neutra, podendo representar tanto um processo de resistência, quanto de uma possível naturalização e incorporação dessa estrutura. Dessa forma, a relação entre o conhecimento oficial e a relação do docente com esse conhecimento, não pode ser compreendida a partir de um caráter neutro ou linear, mas de movimento da atuação docente. Entendendo-se que a posição docente "não é neutra nem nas formas de capital cultural distribuído e empregado pelas escolas e nem nos resultados econômicos e culturais do próprio empreendimento de escolarização" (APPLE, 2006, p. 46-47).

Outra questão identificada neste estudo, que se caracteriza como um campo de conflitos entre questões cotidianamente estabelecidas enquanto dominantes, e processos que se contrapõem a este, refere-se à interdisciplinaridade e a disciplinaridade discutidas a seguir.

O processo de inserção da temática ambiental nos currículos dos cursos se apresenta predominantemente em disciplinas que, em sua maioria, são optativas, presentes na estrutura curricular ou que, posteriormente, irão compor a estrutura curricular após a reestruturação do PPC, tal como explicitado por um dos coordenadores do campus II. De acordo com seu depoimento: "[...] algumas disciplinas que acabam focando um pouquinho nisso, mas de forma geral mesmo [...] mas a parte ambiental vai entrar logo nos currículos, vai entrar no PPC uma disciplina, acho que de Educação Ambiental [...]”.

Já para um dos professores do campus II, a Educação Ambiental é uma temática que não deveria restringir-se a uma disciplina, mas perpassar outras disciplinas. Veja-se: “[...] não trabalho com Educação Ambiental, mas eu acho que as ideias de um cidadão consciente, ela tem que estar embutida em tudo, eu acho que se as disciplinas fossem bem trabalhadas não se precisaria de uma disciplina de Educação Ambiental [...]".

Além da compreensão de que a EA não poderia restringir-se a uma disciplina, o professor critica o discurso que defende a interdisciplinaridade "que tanto se fala”, mas na prática não se concretiza. Segundo o professor,

[...] acho que é uma coisa importante a relação entre a interdisciplinaridade que tanto se fala, uma coisa super na moda é a interdisciplinaridade, mas não faz sentido você ficar falando sobre a interdisciplinaridade se você vai dar uma aula e não faz um link da tua aula com aquela aula do outro [...] está tudo interligado minha gente não tem essa separação, essa separação é para facilitar a compreensão [...] (Professor do campus II).

Mesmo existindo a compreensão da necessidade da interdisciplinaridade há, na verdade, um processo de disciplinarização da inserção da temática ambiental no currículo dos cursos, condição essa, também, observada por Oliveira (2011) ao 
analisar Projetos Políticos Pedagógicos do curso de Pedagogia nas universidades federais do país. A autora, ao identificar as disciplinas que abordam a temática ambiental, menciona que na "maioria das vezes, se caracterizam como disciplinas específicas no tratamento das questões ambientais. Tal fato se mostra interessante, uma vez que a PNEA não indica a abordagem da temática na formação inicial através de disciplinas, e sim de maneira interdisciplinar" (p. 148).

A inserção da temática ambiental nos currículos é um cenário de conflitos entre a necessidade de uma abordagem interdisciplinar, mas tendo marcadamente a disciplinarização. Fato também destacado por Rink (2014, p. 138), ao analisar pesquisas em Educação Ambiental que se voltam para processos de Ambientalização Curricular e, segundo a autora, "muitos pesquisadores mostramse explicitamente contrários a essa perspectiva disciplinar, mas discorrem sobre tal estratégia ser necessária para 'abrir espaço para as discussões' ou 'dar o pontapé inicial' em direção à ambientalização curricular do curso como um todo”.

Para um dos professores do campus I, deveria haver mais ações que pudessem envolver alunos e professores ligados ao curso para discutir questões consideradas importantes para formação docente, tais como as questões ambientais. Entretanto, mesmo existindo uma contextualização por parte das disciplinas, a falta de integralização das áreas que constituem o curso e da articulação entre os professores, caracteriza-se enquanto um dos principais desafios enfrentados pelo curso para realização dessas atividades, tendo como consequência a fragmentação das ações e do próprio conhecimento ao longo do curso. Para esse professor não há um trabalho de forma integrada "[...] então o que cada um faz na sua disciplina é próprio dela, então não há um planejamento articulado para tratar temáticas ou de desenvolver algo que seja de problemas comuns ou que seja de enfoques comuns [...]”.

Essa desarticulação ou fragmentação da ação docente não é uma particularidade do contexto investigado, mas como destacado por Rink (2014), nos trabalhos de teses e dissertações que tratam sobre cursos de licenciatura, "A desarticulação entre disciplinas específicas e disciplinas de caráter pedagógico que compõem o currículo dos cursos é apontada em diversas situações como entrave à inserção da temática ambiental na formação docente" (p. 145). A desarticulação entre os docentes também foi mencionada por um dos professores do campus III que relata o isolamento que envolve a atuação docente e a construção do perfil ou identidade do curso. De acordo com esse professor

[...] a cada dia que passa eu me sinto mais isolado do trabalho, como um todo, na formação dos estudantes da Biologia, algumas dificuldades de relações pessoais, de relações epistemológicas, eu diria. Eu acho que a gente tem um curso com iniciativas muito isoladas, cada um faz o seu e a gente não conversa sobre esse perfil ou pelo menos eu não participo de nenhuma conversa, de nenhuma discussão pedagógica de que alunos nós estamos formando (Professor do campus III).

Tal situação pode estar sendo influenciada pelo caráter "solitário" ou restrito a um determinado grupo de professores, que acabam trabalhando com a temática ambiental em suas disciplinas ou desenvolvem projetos na área.

A interdisciplinaridade pode se constituir como uma possibilidade para "questionar os limites disciplinares e explorar novos horizontes do conhecimento", 
mas, ao mesmo tempo, é necessário levar em conta que "a maior parte das abordagens da interdisciplinaridade se mantém dentro da racionalidade científica moderna" (ESCHENHAGEN, 2009, p. 49). Assim, considerando que as bases que fundamentam a construção do conhecimento correspondem à constituição da visão de mundo prevalecente, a disciplinarização de algumas questões, como a temática ambiental decorre, também, de uma visão fragmentária e objetiva do conhecimento.

Segundo González-Gaudiano et al. (2015), uma das limitações para o processo de inserção da temática ambiental no currículo das universidades consiste no excesso de disciplinas e compartimentalização presente nas estruturas curriculares e que persistem na maioria das universidades, não permitindo que haja certa aproximação entre as questões mais particulares e globais da crise ambiental. A fragmentação que envolve a organização acadêmica constitui-se como um dos principais obstáculos para interdisciplinaridade conduzindo pesquisadores a simplificarem questões que exigem construções complexas, como o meio ambiente e, consequentemente, as iniciativas propostas para pensar essas questões que são pontuais e não permitem a problematização das raízes da crise ambiental (GARCÍA, 2001).

\section{CONSIDERAÇÕES FINAIS}

Ao investigar o processo de Ambientalização Curricular dos cursos de Ciências Biológicas da Universidade Federal de Campina Grande(UFCG) oferecidos nos campi I, II e III observou-se que esses cursos têm incorporado a temática ambiental em seus currículos. Essa temática se concentra, predominantemente, em componentes curriculares optativos nas estruturas curriculares dos cursos.

A concentração dessa temática nas disciplinas optativas pode ser interpretada como uma expressão da secundarização da temática ambiental, a qual, mesmo presente na estrutura curricular, sugere que as questões que suscita, provavelmente, não são avaliadas como constituintes prioritárias na formação desses profissionais. Mas, principalmente, podem ser compreendida como reflexos das condições de produção do currículo desses cursos que envolvem diversos fatores, desde as exigências de políticas curriculares oficiais e da própria instituição no qual o curso está alocado, quanto a formação e interesses dos docentes que elaboraram o PPC.

Nos componentes curriculares dos cursos e a partir das entrevistas com os participantes da pesquisa alguns indícios do processo de Ambientalização curricular puderam ser observados, a partir da abordagem de alguns aspectos da temática ambiental, dentre os quais se evidenciam: a sustentabilidade e o desenvolvimento sustentável; a conservação do ambiente; a interferência das atividades humanas na natureza; a relação sociedade-natureza e o "conhecimento ecológico tradicional".

A partir do material analisado, alguns aspectos identificados podem ser compreendidos como desafios para a efetivação do processo de Ambientalização, como a relação entre o conhecimento oficial e o conhecimento ensinado, e a interdisciplinaridade e disciplinaridade. Tais aspectos não se restringem à Ambientalização curricular, mas circunscrevem o contex to no qual esta se desenvolve.

Além desses, considera-se que outros fatores influenciam esse processo nos cursos de Ciências Biológicas investigados, tais como a formação inicial e 
continuada dos docentes que atuam nos cursos, assim como as ações de pesquisa e extensão desenvolvidas a partir dos interesses desses docentes.

Frente às análises dos dados, compreende-se que a ação conjunta entre professores e alunos pode favorecer a inserção da temática ambiental nos cursos analisados, tendo em vista a importância da participação do aluno, tanto em sala de aula, quanto em atividades em outros espaços da Universidade, tais como grupos de pesquisas, atividades de extensão e pesquisas coordenadas pelos docentes. Assim, iniciativas que privilegiem um planejamento articulado entre docentes e alunos podem possibilitar o enfrentamento em relação à fragmentação do conhecimento, bem como contribuir para a compreensão da complexidade que envolve as questões referentes à relação sociedade-natureza.

O processo de Ambientalização Curricular não se restringe à incorporação da temática ambiental nas ementas das disciplinas, mas, como um fenômeno complexo que exige envolvimento e articulação das iniciativas que se voltam para essa temática entre docentes, alunos e direção, tendo em vista as condições do contexto no qual o currículo é produzido.

Além disso, mesmo que os cursos de Ciências Biológicas desenvolvam suas atividades ligadas às discussões ambientais, é necessário também investigar por que determinadas temáticas são privilegiadas em detrimento de outras nos Projetos Pedagógicos dos cursos de Ciências Biológicas?

Assim, torna-se necessário o desenvolvimento de outros estudos que possam contribuir para a compreensão e reflexão acerca da Ambientalização no ensino superior.

\section{REFERÊNCIAS}

ADORNO, T. W. e HORKHEIMER, M. Dialética do Esclarecimento: fragmentos filosóficos, tradução Guido Antonio de Almeida, Rio de Janeiro: Jorge Zahar Ed., 1985.

APPLE, M.W. Ideologia e Currículo. Tradução Vinicius Figueira. Porto Alegre: Artmed, 2006.

CARVALHO, I. C. M. Educação ambiental: a formação do sujeito ecológico. São Paulo: Cortez Editora, 2004.

CARVALHO, I. C. M; SILVA, R. C. Ambientalização do ensino superior e a experiência da Pontifícia Universidade Católica do Rio Grande do Sul. In: RUSCHEINSKY, A. et al. (org.) Ambientalização nas instituições de educação superior no Brasil: caminhos trilhados, desafios e possibilidades. São Carlos: EESC/USP, p. 125-144, 2014.

CARVALHO, L. M; CAVALARI, R. M. F; SILVA. D.S. Ambientalização nas instituições de ensino superior: as teses e dissertações em Educação Ambiental desenvolvidas no Brasil. In: GUERRA, A. F. S. (org.). Ambientalização e sustentabilidade nas universidades: subsídios, reflexões e aprendizagens. $1^{a}$ ed. Dados eletrônicos, Itajaí: Editora da Univali, p. 48-65, 2015.

FIGUEIREDO, M. L.; JUNKES, M. M; ZUNINO, H. M. W.; AIUB, G. W; STEUCK, E. R. O processo de Ambientalização no Centro Universitário de Brusque: A aplicação de um Sistema de Indicadores de Sustentabilidade. In: Contrapontos, Itajaí, v. 15, n. 2, p. 185-203, 2015. 
GARCÍA, M.C. La ambientalización de la Universidad: um estúdio sobre la formación ambiental de los estudiantes de la universidad de Santiago de Compostela y la política ambiental de la institución. 2001. p. 610. Tese (Doctorado em ciencias de la Educación)- Universidad de Santiago de Compostela, Facultad Ciencias de la Educaión, Santiago de Campostela, 2001.

GONZALEZ, L. T. V. A temática ambiental e os cursos superiores de Turismo. 2008. 120p. Dissertação (Mestrado em Educação) - UNESP, Rio Claro, 2008.

GONZÁLEZ-GAUDIANO, E. J. G; MEIRA-CARTEA, P. Á; MARTÍNEZ-FERNÁNDEZ. Sustentabilidad y Universidad: retos, ritos y posibles rutas. In: Revista de la Educación Superior. v. XLIV, n.175, 2015.

GUTIÉRREZ, J; BENAYAS, J; CALVO, S. Educación para el desarrollo sostenible: evaluación de retos y oportuanidades del decenio 2005-2014. In: OEI- Revista Iberoamericana de Educación. n. 40, 2006.

LEFF, E. Discursos sustentáveis. São Paulo: Cortez, 2010.

LEFF, E. Prólogo. In: ESCHENHAGEM, M. L. Educación Ambiental Superior em América Latina. Bogotá. Echoe, Ediciones, 2009.

LEFF, E. Saber ambiental: sustentabilidade, racionalidade, complexidade, poder. $6^{a}$ ed. Petrópolis, RJ: Vozes, 2008.

LÜDKE, M; ANDRÉ, M. E. D. A. Pesquisa em educação: abordagens qualitativas. São Paulo: EPU, 1986.

MEDEIROS, R.; IRVING, M.; GARAY, I. A Proteção da Natureza no Brasil: evolução e conflitos de um modelo em construção. Revista de Desenvolvimento Econômico, Salvador, v. 6, n. 9, p. 83-93, Jan. 2004.

OLIVEIRA JÚNIOR, W. M. et al. As 10 características em uma diagrama circular. In: JUNYENT, M; GELI, A. M; ARBAT, G.E. (ed.) Ambientalizaçión curricular de los estudios supeiores: processo de caracterización de la ambientalización curricular de los estudios universitarios. Girona, Red Aces. v. 2, 2003.

OLIVEIRA, M.G. Cursos de Pedagogia em Universidades federais brasileiras: políticas públicas e processos de ambientalização curricular. 2011,169 p. Dissertação (Mestrado em Educação) - Universidade Estadual Paulista "Júlio de Mesquita Filho", Instituto de Biociências, campus de Rio Claro, 2011.

PAVESI, A. A ambientalização da formação do arquiteto: o caso do curso de Arquitetura da Escola de Engenharia de São Carlos (CAU, EESC-USP). 2007. 199p. Tese (Tese de Doutorado) Universidade Federal de São Carlos, São Carlos, 2007.

PENAGOS, W. M. M. La inclusión de la dimensión ambiental en la educación superior: un estúdio de caso en la facultad de medio ambiente de la universidad distrital en Bogotá. 2011, 401p. Tese (Doctorado intereruniversitario de educación ambiental) Facultad de ciencias de la educación, Universidad de Sevilla, 2011.

RINK, J. Ambientalização curricular na educação superior: tendências reveladas pela pesquisa acadêmica brasileira (1987-2009). 2014, 221p. Tese (Doutorado em Educação) - Universidade Estadual de Campinas, Faculdade de Educação, Câmpus de Campinas, 2014. 
SACRISTÁN, J. G. O currículo: uma reflexão sobre a prática. $3^{\mathrm{a}}$ ed. Porto Alegre: Artmed, 2000.

SILVA, M.D. A Ambientalização Curricular no curso de formação de professores de Ciências e Biologia na percepção dos licenciandos. 2014, 121p. Dissertação (Mestrado em Educação) - Universidade Federal de São Carlos, Centro de Educação e Ciências Humanas, Câmpus de São Carlos, 2014.

YIN, R.K. Estudo de caso: planejamento e métodos. $4^{\mathrm{a}}$ ed. Porto Alegre: Bookman, 2010.

\section{NOTAS}

${ }^{1}$ A Pegada Ecológica é uma metodologia de contabilidade ambiental que avalia a pressão do consumo das populações humanas sobre os recursos naturais (WWF). Mais informações em: http://www. wwf.org.br/natureza_brasileira/especiais/pegada_ecologica/

22 A "Rede de Ambientalización Curricular de los Estudios Superiores" (Red Aces) foi um projeto desenvolvido no período de 2001-2004 e envolveu onze universidades, sendo cinco europeias e seis latino-americanas: Universidade Nacional de Cuyo e Universidade de San Luis na Argentina; Universidade Estadual de Campinas, Universidade Estadual Paulista - Rio Claro e Universidade Federal de São Carlos no Brasil; e Universidade de Pinar del Río "Hermanos Saíz Montes de Oca" em Cuba. Durante esse projeto, os pesquisadores participantes atuaram na construção de indicadores para caracterizar um currículo ambientalizado.

${ }^{3}$ A Ariusa foi criada em Bogotá, em 2007, por um grupo de Redes Universitárias em Ambiente e Sustentabilidade (Ruas), entre as redes universitárias participantes da Ariusa está a Rede sul brasileira de Educação Ambiental (Reasul).

${ }^{4}$ Neste texto compreendemos que a temática ambiental corresponde a toda temática que faz referência à natureza ou meio ambiente incluindo as relações socioambientais, mas como o curso investigado tem como uma das suas bases o estudo da natureza decidimos delimitar esta temática a relação sociedade natureza, dessa forma ao longo do texto utilizaremos temática ambiental enquanto sinônimo de relação sociedade natureza.

${ }^{5}$ São "grupos que conquistam ou estão lutando para conquistar identidade pública que inclui algumas características: uso de técnicas ambientais de baixo impacto; formas equitativas de organização social; presença de instituições com legitimidade para fazer cumprir suas leis; e, por fim, traços culturais que são seletivamente reafirmados e reelaborados". (CUNHA e ALMEIDA, 2001, p.192).

\section{Submetido em 22/09/2017 \\ Aprovado em 15/03/2018}

\section{Contato:}

Dayane dos Santos Silva

Universidade Estadual Paulista "Júlio de Mesquita Filho"

Departamento de Educação

Avenida $24 \mathrm{~A}, \mathrm{n}^{\circ} 1515$

CEP: $13506-900$ - Rio Claro, SP - Brasil 